\title{
Differences in Electromyography during Self-Compassionate and Self-Critical Imageries According to the Level of Self-Criticism
}

\author{
Jana Koróniová ${ }^{\text {(D) , Júlia Halamová2 }}{ }^{\text {(D) Zuzana Džongová }}{ }^{2}$ \\ ${ }^{1}$ Institute of Experimental Psychology, Center of Social and Psychological Sciences, Slovak Academy of Sciences, \\ Dúbravská cesta 9, 84104 Bratislava, Slovak Republic \\ ${ }^{2}$ Institute of Applied Psychology, Faculty of Social and Economic Sciences, Comenius University in Bratislava, Mlynské \\ luhy 4, 82105 Bratislava, Slovak Republic
}

\begin{abstract}
The aim of this study was to analyze changes in muscle activity between high and low self-critical participants during the imagery of self-compassion, self-protection, and self-criticism. Muscle activity was measured by the Biopac MP36 while participants were listening to the imagery audio recording. Levels of self-criticism were measured by The Forms of Self-Criticising/Attacking and Self-Reassuring Scale (FSCRS; Gilbert et al., 2004). From overall number of 110 participants, 30 participants were selected for further analysis based on their extreme level of self-criticism. The research sample consisted of 15 participants with high level of self-criticism and 15 with low level of self-criticism. The results showed that participants with higher levels of self-criticism had similar levels of muscle activity during the self-critical and self-protective phases of imagery. However, during the last self-compassionate imagery, participants with lower self-criticism returned to the baseline EMG levels, while those with higher self-criticism remained at high EMG levels. The results showed lower muscle activity in low self-critics while imagining inner compassionate part meaning. Therefore, low self-critics are probably better able to calm themselves down compared to high self-critics.
\end{abstract}

Key words: self-criticism, self-protection, self-compassion, electromyography, imagery

\section{Introduction}

Both self-compassion and self-criticism have been widely discussed and researched psychology topics during the last few years (e.g.,
Seppälä et al., 2017). One of the main reasons for the growing interest is their impact on mental health. There are several interventions focused on cultivating self-compassion and dealing with self-criticism and they seem to be effective in bringing desired results

Correspondence concerning this article should be addressed to Júlia Halamová, Institute of Applied Psychology, Faculty of Social and Economic Sciences, Comenius University in Bratislava, Mlynské luhy 4, 82105 Bratislava, Slovak Republic. E-mail: julia.halamova@gmail.com

Received February 23, 2020 
(Kirby, 2016). The outcome is obtained mainly by using self-reported methods; therefore, the reliability is limited. Although there are studies dealing with self-compassion and self-criticism interventions on a physiological level, they are rather scarce (e.g., Halamová, Koróniová, Kanovský, Kenésy Túnyiová, \& Kupeli, 2019). Our major aim is to fill the gap on the physiology level using Electromyography (EMG), because this indicator, in comparison with heart rate variability (HRV; Kirby, Doty, Petrocchi, \& Gilbert, 2017), seems to have been left out even though the link between emotions and muscle activity appears to be obvious (Künecke, Hildebrandt, Recio, Sommer, \& Wilhelm, 2014). Therefore, we expected that EMG could be a relevant indicator for measuring the level of self-compassion and self-criticism. In comparison with the more often examined physiological indicators such as HRV, using EMG could broaden the field of measuring intervention effectivity by muscle activity.

\section{Self-Compassion}

Compassion towards self could be defined in terms of compassion focused inwards, in situations of suffering from failure, by accepting one's own imperfections, not avoiding them, and understanding them as a universal human experience (Neff \& Germer, 2013). Self-compassion also cultivates compassion towards others (Neff, 2003). On the other hand, Gilbert (2010b) sees compassion as a sensitivity coupled with motivation and caring for oneself, which also includes tolerating negative feelings emerging from negative life events. Some authors refer that self-compassion serves as a protective mechanism and contributes to maintaining mental health (Muris et al., 2015). Although, according to Strauss et al. (2016), compassion towards self or others is a cognitive, behavioral, and affective pro- cess consisting of five elements: recognizing suffering, understanding the universality of suffering in human experience, feeling empathy for the person suffering and connecting with the distress, tolerating uncomfortable feelings aroused in response to the suffering person, and motivation to alleviate suffering.

\section{Self-Criticism}

Self-criticism is believed to be a base for all sorts of psychopathology (Castilho, Pinto-Gouveia, \& Duarte, 2013) and negative self-evaluation focused mainly on appearance, thoughts, emotions or behavior (Longe et al., 2010). Self-critical people fail to meet the goals they have set (Blatt \& Zuroff, 1992), which often makes them feel insufficient, guilty, helpless, hopeless or insecure (Gilbert, Clarke, Hempel, Miles, \& Irons, 2004). Gilbert (1989) defines self-criticism as anger and attack focused towards self, mainly in situations of failure. Straub (1991) defines self-criticism in terms of vulnerability and poor self-identity, where the main purpose is to prevent possible mistakes in order to improve oneself. Gilbert and Irons (2004) describe it as a shame-based process because the self is perceived as inadequate and undesirable. The treatment of self-criticism appears to be very difficult, because it is a relatively stable personality trait (Zuroff, Sadikaj, Kelly, \& Leybman, 2015) and some of its aspects are very difficult to change (Werner et al., 2019).

\section{Self-Protection}

Alicke and Sedikies (2009) pointed out that self-protection applies to the pursuit of pleasant experiences and avoidance of negative ones. They found that people tend to present themselves in as positive a light as possible and minimize their negative traits or features. Self-protection can be viewed as a protective 
mechanism in the context of mental health (Muris et al., 2015) as it engages protective anger (e.g., Timulak, 2015). The ability of being self-protective is tightly bound to anger. However, there are quite a few types of anger that therapists work with but not all of them can be considered to be protective or "healthy". For example, rejecting anger is characteristic by irritability and high reactivity to behavior of other people (Pascual-Leone et al., 2013). Authors imply, that this kind of anger is rather nonspecific or secondary. On the other hand, protective anger (known also as assertive anger) is providing an answer to unmet needs in core emotional pain and ensuring strength and support for oneself as a response to former mistreatment (Timulak \& Pascual-Leone, 2014). Pascual-Leone and Greenberg (2007) found that an individual with poor self-evaluation will have great difficulty generating protective anger. They also implied that protective anger is mainly aimed at setting boundaries and standing up for one's rights, and not at ignoring harmful things.

\section{Electromyography}

Electromyography is a method widely used in psychology, mainly in the field of emotions and emotion perception (e.g., Künecke et al., 2014), for example, for detecting emotional valency (Hazlett \& Benedek, 2007) or emotional activity (Dimberg, 1990) because this technique allows for recording and evaluating electric impulses from skeletal (voluntary) muscles. The principle is, that face muscles are still until a force of contraction increases and causes muscle activity (Mills, 2005). Witvliet, Knoll, Hinnman, and DeYoung (2010) found, that experiencing compassion reduced not only muscle activity but also decelerated heart rate. Overall, compassion and self-compassion are characterized by positive emotions (Whelton \& Greenberg, 2005) displayed mainly by a smile, which engages the zygomaticus major (Sato, Fujimura, \& Suzuki, 2008), a muscle located on the cheeks. On the other hand, self-critical and depressed people tend to show significantly higher muscle activity in comparison with non-depressed sample (Schwartz, Fair, Salt, Mandel, \& Klerman, 1976). Studies using electromyography also found, that mimicking emotional facial expressions of others stimulates the corresponding regions in the perceiver, which is an unconscious process (Niedenthal et al., 2010). However, this may not always be true. For example, dysphoric people show impaired interpersonal reactivity to happy expressions (Sloan et al., 2002). Research has also confirmed, that not only immediate presence of emotional faces but also mental imagery can cause changes in EMG activity (Suess \& Rahman, 2015).

\section{Aims}

The present study explores the differences in EMG muscle activity related to levels of self-criticism measured by FSCRS during self-critical, self-protective, and self-compassionate imagery. Electromyography has the potential to be as relevant a physiological indicator of self-compassion and self-criticism as HRV, but it has not been examined sufficiently to date. Therefore, we supposed that EMG could be used as a relevant physiological indicator of the level of self-compassion and self-criticism by measuring their intervention effectivity by muscle activity.

\section{Method}

\section{Participants}

The sample size was calculated by the G*Power program (version 3.1.9.2), for repeated mea- 
sures, within-between interaction, power 0.80, alpha error probability 0.05 , number of groups 2 , number of measurements 4 , with the result that the total sample size should be 24 .

Our sample consisted of university students of psychology. At the beginning, an invitation e-mail was sent to all psychology students at the Faculty of Social and Economic Sciences in Bratislava. All the students, who completed the research measurement received extra course credits for their participation. The students were free to sign in regardless of their year of study and the invitation was sent to them by e-mail. Participation was voluntary and all participants received a reminder e-mail 24 hours before the measurement. Those interested signed in online using their personal code. A total of 110 students completed the measures, however, 11 needed to be excluded due to errors in the EMG record. The final group of students was established using their extreme values in self-criticism (either low or high), resulting in the final sample of 15 low self-critics and 15 high self-critics, aged between 19 - 24 years old $(A M=21.13$; $S D=1.19)$. The extreme values were based on the Slovak norms for FCSRS (Halamová \& Kanovský, 2017). The group of high self-critics contained 15 people whose score in the subscale of Hated self was 9 or higher. The 15 low self-critics, on the other hand, was determined by Hated self score of 2 and lower. Therefore, the final number of 30 people was created from the most high and the most low self-critics. The sample of only young people was chosen intentionally, because research suggests, that young adults tend to be more self-critical than older people ( $\mathrm{O}^{\prime}$ Connor \& Noyce, 2008).

\section{Procedure}

Following completion of the informed consent form and socio-demographic questions, electrodes of BIOPAC MP36 were applied. To measure muscle activity, the electrodes were pasted to a person's forehead and right cheek and secured by a bandage to prevent them from peeling off. All participants were asked to follow the imagery audiotape (including relaxation, self-criticism, self-protection, and self-compassion). Just after the imagery tasks, participants completed an online FSCRS form measuring their levels of self-criticism.

\section{Guided Imagery Task}

The imagery task was created by the first and second authors of this study based on the findings of Emotion-focused therapy for dealing with a self-critic (Pascual-Leone \& Greenberg, 2007). The whole guided imagery task took 10 minutes and to standardize the task, all participants listened to the instructions from a pre-recorded audiotape. The imagery task was provided in a lab with a research assistant, who attached the electrodes as described above and swiched on the recording. The tasks were designed to elicit relaxation, self-criticism, self-protection, and self-compassion. Following each instruction, participants were given 30 seconds in silence to complete the imagination task.

The exercise began with a relaxation instruction involving closing their eyes and concentrating on breathing and relaxing their muscles. This was followed by instructions of guided imagery designed to trigger feelings of self-criticism. The instructions were to remember a recent situation when the participants felt uncomfortable because of their own criticism, to imagine the part of them that was criticizing or attacking and imagine how they would react to this experience of self-criticism. The second task involved eliciting feelings of self-protection. Participants were instructed to imagine the part of them that wanted to defend them against their in- 
ner critic when experiencing feelings of failure, what they did to protect themselves, and what they felt during this process. The final task involved eliciting feelings of self-compassion, which involved imagining their self-compassionate part that is loving, accepting, warm, and supporting in a situation of failure and experiencing how they respond to self-compassion. For each part we asked two main questions: 1) Please, describe as detailed as possible your self-critical/self-protective/self-compassionate part, which you have just imagined (What exactly did it tell you? How did it tell you that? What did it look like? etc.); 2) Please, write as detailed as possible about your inner experience when you imagined your self-critical/self-protective/self-compassionate part (How did you feel? What did you think? What were you doing? What behavioral tendencies did you find in yourself? What did you need then? etc.).

\section{Measures}

\section{Psychophysiological Measures}

\section{Electromyography}

To measure physiological data, the Biopac MP36 was used. The system consists of four channels to detect the signal from various physiological actions. The signal is detected by fully shielded adapters with pinch connectors and disposable $\mathrm{Ag} / \mathrm{AgCl}$ electrodes. The Biopac software was used to record and subsequently evaluate the data obtained from the Biopac hardware. Electrodes were attached to participant's face, more specifically on the right cheek and right above both eyebrows, to detect the corrugator supercili (frowning muscle) activity, because this specific muscle is believed to be activated in high self-critics (e.g., Rhode, Adolph, Deitrich, \& Michalak, 2014). The electrodes were secured by elastic bandage, which prevented them from moving or detaching from the skin. The EMG signal was analyzed by the Biopac MP36 software - more specifically the AcqKnowledge system - and we extracted measurements from multiple contractions during the whole imagery. The imagery consisted of three parts - self-critical, self-protective and self-compassionate, where each part was analyzed separately. The Biopac MP36 software belongs to the older versions of the AcqKnowledge system so we needed to anticipate a manual scoring. The obtained graph represented the magnitude as a function of frequency. The FFT (a fast Fourier transform) magnitude needed to be normalized by using the integral function in the AcqKnowledge and then the final measurements were obtained. Our sample had no normal distribution and, therefore, we used the Median Frequency $(\mathrm{Hz})$ representing a frequency in which $50 \%$ of the total power within the epoch is reached. The final measurements were reported in the unit of Hertz.

\section{Self-Reported Measures}

The Forms of Self-Criticising/Attacking and Self-Reassuring Scale (FSCRS; Gilbert et al., 2004). The FSCRS is a 22-item self-report measure with the following subscales: Reassured-self (RS), Inadequate-self (IS), and Hated-self (HS). The FSCRS requires participants to rate a selection of positive and negative statements on a 5-point Likert scale ("Not at all like me" to "Extremely like me"). Positive items reflect the ability to self-reassure (referred to as reassured-self) and negative items indicate self-critical thoughts and feelings (split into subscales of inadequate-self and hated-self). The questionnaire consists of three subscales: Reassured-self ("I still like being me"), Inadequate-self ("I am easily disappointed with myself"), and Hated-self ("I have become so angry with myself that I want to hurt or injure myself"). The psychometric 
properties and factor structure of this scale have been validated in 13 different nonclinical samples across 12 countries (Halamová et al., 2018) as well as in the Slovak population (Halamová, Kanovský, \& Pacúchová, 2017). The values for Cronbach's alpha for the current study were $0.81,0.88$ and 0.73 for Inadequate Self, Reassured Self, and Hated Self, respectively.

\section{Data analysis}

The data were recorded in SPSS 22, and analyzed in program R 3. 5. 1. (R Core Team, 2018), package "nlme" (Pinheiro et al., 2015) and „robustlmm" (Koller, 2016).

\section{Results}

The sample of participants consisted of 15 high self-critics and 15 low self-critics and the groups were established by calculating of the FSCRS raw score, more specifically the raw

Table 1 Descriptive statistics for FSCRS

\begin{tabular}{lccccccc}
\hline & $S D$ & $A M$ & Median & Min & Max & $R$ & $V K$ \\
\hline High self-critics & 3.04 & 11.2 & 10 & 9 & 18 & 9 & 27.12 \\
Low self-critics & 0.89 & 1 & 1 & 0 & 2 & 2 & 89.44 \\
\hline
\end{tabular}

Note. $\mathrm{SD}=$ Standard deviation, $\mathrm{AM}=$ means, Min = minimum, Max = Maximum, $\mathrm{R}=$ Range, VK = Coefficient of va riation.

Table 2 Descriptive statistics of EMG for high self-critics

\begin{tabular}{lcccc}
\hline Descriptive statistics & Baseline & Self-Critic & Self-Protector & Self-Compassion \\
\hline AM & 126.38 & 129.77 & 127.35 & 125.05 \\
Median & 137.37 & 143.32 & 141.25 & 137.97 \\
SD & 35.97 & 35.42 & 35.63 & 35.23 \\
Min & 29.75 & 30.02 & 30.30 & 25.18 \\
Max & 182.98 & 186.83 & 215.54 & 183.53 \\
$R$ & 153.23 & 156.81 & 185.24 & 158.35 \\
VK & 28.46 & 27.30 & 27.98 & 28.17 \\
\hline
\end{tabular}

Note. SD = Standard deviation, $\mathrm{AM}=$ mean, Min = Minimum, Max = Maximum, $\mathrm{R}=$ range, $\mathrm{VK}=$ Coefficient of va riation. 
normally and therefore classic linear regression was not suitable to use. Our data violated the assumption of answer independence, because every participant provided 10 measurements ( 1 measurement for relaxation and 3 measurements for imagination of the three parts of the self), which necessitated the use of multilevel models. We used the R program, more specifically the libraries "nlme" (Pinheiro et al., 2015) and "robustlmm" (Koller, 2016) to analyze the data. In a multilevel model, more complex models are gradually tested by adding parameters and verifying which is the best match for the data. There are no parameters in a zero model, but they are added gradually. First, the random effect, which represents the differences between individuals, and later on the fixed effects which stand for the differences in groups, differences in time and their mutual interaction. The plausibility test verifies whether adding parameters improves model compliance with data. If any of the parameters does not improve the match with the data, it makes no sense to add it to the model. Further, we used information criteria (AIC and BIC) to prevent the model from being artificially improved. If the model has larger values than the information criteria in the previous model, although it is more complex, it is a better match with the

Table 3 Descriptive statistics of EMG for low self-critics

\begin{tabular}{lrrrr}
\hline Descriptive statistics & Baseline & Self-Critic & Self-Protector & Self-Compassion \\
\hline AM & 121.14 & 130.20 & 125.81 & 123.84 \\
Median & 134.84 & 140.05 & 125.81 & 134.00 \\
$S D$ & 47.78 & 38.90 & 39.72 & 40.24 \\
Min & 19.65 & 24.96 & 24.68 & 25.26 \\
Max & 213.01 & 214.41 & 213.71 & 204.04 \\
$R$ & 193.36 & 189.45 & 189.03 & 178.78 \\
VK & 39.44 & 29.87 & 31.58 & 32.49 \\
\hline
\end{tabular}

Note. SD = Standard deviation, $\mathrm{AM}=$ mean, Min = Minimum, Max = Maximum, $\mathrm{R}=$ range, VK = Coefficient of variation.

Table 4 Parameters of classic and robust model

\begin{tabular}{|c|c|c|c|c|}
\hline & \multicolumn{2}{|c|}{ Classic model } & \multicolumn{2}{|c|}{ Robust model } \\
\hline & $B(\mathrm{SE})$ & $t$-value & $B(\mathrm{SE})$ & $t$-value \\
\hline Baseline & 81.38 (7.17) & $11.36 * * *$ & $91.93(5.75)$ & $15.98 * * *$ \\
\hline Crit2 & 10.52 (10.13) & $1.94 \mathrm{~ns}$ & $2.00(8.14)$ & $0.25 \mathrm{~ns}$ \\
\hline Seq1 & 10.09 (2.66) & $7.54 * * *$ & $8.66(1.72)$ & $5.03 * * *$ \\
\hline Seq2 & $14.56(2.66)$ & $5.47^{* * *}$ & $2.78(1.72)$ & $1.61 \mathrm{~ns}$ \\
\hline Seq3 & $8.19(2.66)$ & $3.07 * *$ & $-1.55(1.72)$ & $-0.90 \mathrm{~ns}$ \\
\hline Crit2:Seq1 & $-12.67(3.77)$ & $-3.36 * * *$ & $-0.54(2.43)$ & $-0.22 \mathrm{~ns}$ \\
\hline Crit2:Seq2 & $-9.29(3.77)$ & $-2.47^{*}$ & $1.70(2.43)$ & $0.70 \mathrm{~ns}$ \\
\hline Crit2:Seq3 & $-1.06(3.77)$ & $-0.28 \mathrm{~ns}$ & $9.04(2.43)$ & $3.71 * * *$ \\
\hline
\end{tabular}

Note. 6 = regression coefficient, $\mathrm{SE}=$ standard error, Crit2 $=$ high self-critic, Seq1 = selfcritical sequence, Seq2 $=$ self-protector sequence, seq3 = self-compassion sequence. 
data. In the classic model, extreme values can significantly increase standard errors and skew parameter appraisal, so we used the robust model. In this model all standard errors are much lower. In Table 4 we can see that the parameter estimates in the robust model are different from the classic ones. In the classic model, the main sequence effects are significant, so Seq 1 (self-critic), Seq 2 (self-protector), and Seq 3 (self-compassion) are statistically significantly higher than Baseline, and the values of highly self-critical participants in sequences 1 and 2 are significantly lower than those of low self-critics. In the sequence number 3 they are not significantly different, though. In a robust model, however, only Seq 1 is significantly higher than Baseline. The interaction effects in this model are estimated to be exactly the opposite of the classic model. The values of the high self-critics in Seq 1 and 2 are not significantly different than those of low self-critics, but in Seq 3 they are significantly different.
The results of the robust model show that both groups had significantly increased EMG values in the self-critical sequence compared to Baseline and were not significantly different in the self-protective sequence. The difference occurred in the sequence of self-compassion, where high self-critics remained high in EMG values, but low self-critics returned to EMG values characteristic for Baseline (see Figure 1).

In multilevel models, there are two types of effect sizes $\left(R^{2}\right)$ : marginal (variance explained by fixed factors only) and conditional (variance explained by fixed factors and random factors), see Nakagawa and Schielzeth (2013). The marginal $R^{2}$ is 0.12 , and the conditional $R^{2}$ is 0.88 - since our random effect is ID (taking into account the repeated-measures), the conditional $R^{2}$ adds individual differences. It is clear that much of the variance is explained by individual differences and only minor portion of the variance is explained by fixed effects.

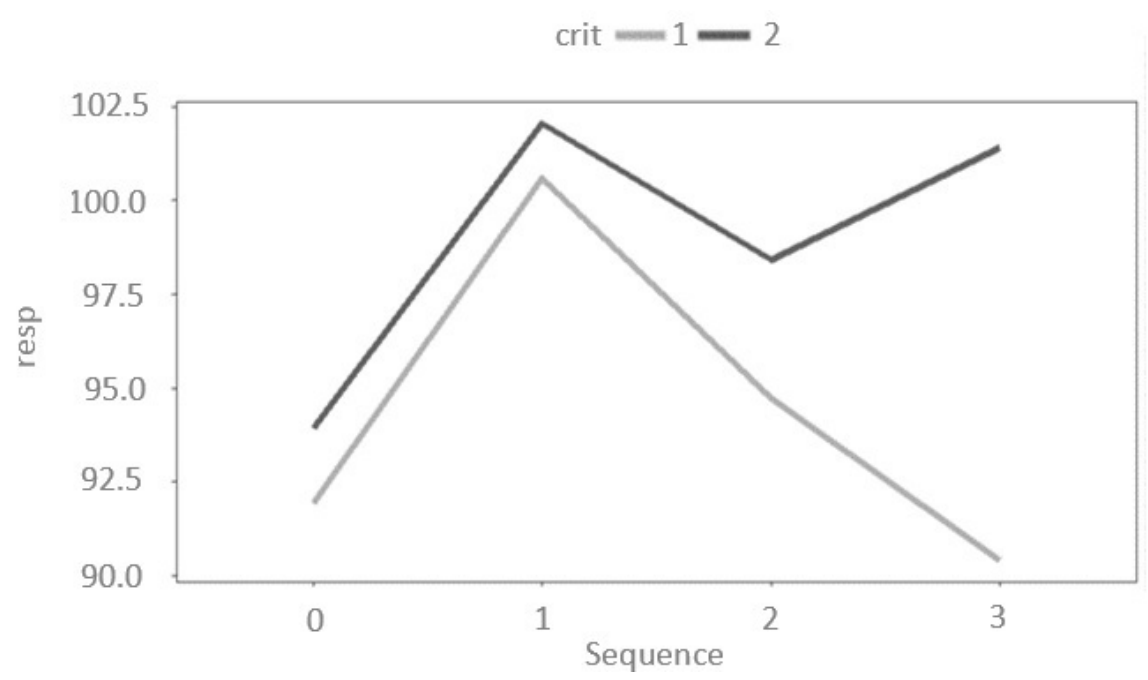

Figure 1 EMG values by groups and sequences.

Note. crit1 = low self-critics, crit2 $=$ high self-critics, Resp = EMG values, Seq01 = baseline sequence, Sequence 1 = self-critical sequence, Sequence 2 = self-protector sequence, Sequence 3 = self-compassion sequence. 


\section{Discussion}

The aim of our study was to analyze the differences in EMG muscle activity related to levels of self-criticism during self-critical, self-protective, and self-compassionate imagery. Based on previous research we can say that self-compassion has a positive and soothing effect on the human body (Petrocchi, Ottaviani, \& Coumyoumdijan, 2016). Imagery has a potential to evoke feelings as well as physiological responses. Gilbert and Procter (2006) report that calming ideas in stressful situations can activate our soothing system. The results showed that the EMG values increased significantly in the self-critical sequence of the imagery compared to the Baseline values. The values of the self-critical and self-protective sequence of the imagery in high self-critics are not significantly different than in low self-critics, but in the last self-compassionate sequence they did differ significantly. The EMG values of low self-critics returned to Baseline values, meaning that they calmed down in this imagery sequence. Our results are consistent with the study of Witvliet, Knoll, Hinman, and DeYoung (2010), who examined heart rate variability along with the muscle activity during compassionate imagery. Participants were supposed to imagine someone who hurt them but then look at the abuser as a human being, who needs positive change or healing. The results showed reduced EMG and reduction in heart rate. The results are also supported by Svendsen et al. (2016), who found that self-compassionate people have a better ability to regulate emotions and experience less stress emotion-related reactions. The main contribution of our work rests in testing EMG in relation with self-criticism and self-compassion since these kinds of studies are still rather limited. The results imply, that self-compassionate imagery has the poten- tial to reduce muscle activity and therefore contribute to relaxation and lower the level of experienced stress. On the other hand, the results implied that high self-critical people showed no change in muscle activity. In other words - muscle activity remained high. The possible explanation is that for highly self-critical people this kind of imagery is insufficient. Also, research suggests that some aspects of self-criticism, especially hated self are very difficult to change (e.g., Werner et al., 2019) and require individual psychological or psychotherapeutic intervention. It is also very likely, that low self-critical people can naturally calm themselves down in situations of criticism, which could be even more sufficient when they experience self-compassion. On the contrary, high self-critics struggle with receiving compassion or self-compassion, which could stress them even more resulting in higher muscle activity. Results imply, that the intervention may not be sufficient for extremely self-critical people, but more importantly, it shows the link between muscle activity and self-criticism.

\section{Limitations}

One of the limits that could possibly influence the results is lack of participants. The sample consisted of 30 people, mostly women, making it impossible to ascertain gender differences. More balanced sample could show different results. Also, the majority of the students had no previous experience with imagery, and we did not further examine the levels of their mental imagery skills. Therefore, we did not know whether the participants had previous experience with imagery exercises and if so, how good they were in imagery techniques. We realize that the participants could have answered on the questionnaire not in the way they felt, but in the way that made them look better. In addition, results could have been 
different if we had selected a sample from the clinical population, in which more differences between the high and low self-critics could be analyzed based on EMG values. On the other hand, had we chosen older populations for the EMG analysis we would have probably found the same differences in EMG between high and low self-critics because age does not significantly influence the level of self-criticism in Slovak samples (Halamová \& Kanovský, 2017).

\section{Conclusion}

The exploration of the relationship between muscle activity during imagery at different levels of self-criticism showed that muscle activity during self-critical imagery was higher for both groups regardless of the self-criticism level. In the self-protection part there was no significant change, but the self-compassionate inner part results showed low self-critics having the same muscle activity as they did at the very beginning of the imagery (relaxation), which could possibly mean that compared to high self-critics they were able to calm down. Our study points out that research on self-compassion and self-criticism should be extended to include EMG measurements, because it brings promising results. As the results show, self-compassion and self-criticism affect numerous bodily systems, and physiological indicators can be a precious indicator for intervention outcome studies.

\section{Availability of Data and Materials}

In order to comply with the ethics approvals of the study protocols, data cannot be made accessible through a public repository. However, data are available upon request for researchers who consent to adhering to the ethical regulations for confidential data.

\section{Acknowledgement}

Writing this work was supported by the Vedecká grantová agentúra VEGA under Grant $1 / 0075 / 19$. We would like to acknowledge Nikoleta Taňkošová for help with data collection. We would like to thank Martin Kanovský for statistical analysis.

\section{Authors' ORCID}

Jana Koróniová

https://orcid.org/0000-0003-4781-0900

Júlia Halamová

https://orcid.org/0000-0002-2655-2327

Zuzana Džongová

https://orcid.org/0000-0003-3473-3889

\section{References}

Alicke, M. D., \& Sedikides, C. (2009). Self-enhancement and self-protection: What they are and what they do. European Review of Social Psychology, 20(1), 1-48. https://doi.org/10.1080/10463280802613866

Blatt, S. J., \& Zuroff, D. C. (1992). Interpersonal relatedness and self-definition: Two prototypes for depression. Clinical Psychology Review, 12(5), 527-562. https://doi.org/10.1016/0272-7358(92)90070-0

Castilho, P., Pinto-Gouveia, J., \& Duarte, J. (2013). Exploring self-criticism: Confirmatory factor analysis of the FSCRS in clinical and nonclinical samples. Clinical Psychology \& Psychotherapy, 22(2), 153164. https://doi.org/10.1002/cpp.1881

Duarte, C., Ferreira, C., \& Pinto-Gouveia, J. (2016). At the core of eating disorders: Overvaluation, social rank, self-criticism and shame in anorexia, bulimia and binge eating disorder. Comprehensive Psychiatry, 66, 123-131. https://doi. org/10.1016/i.comppsych.2016.01.003

Germer, C. K., \& Neff, K. D. (2013). Self-compassion in clinical practice. Journal of Clinical Psychology, 69(8), 856-867. https://doi.org/10.1002/ jclp.22021

Gilbert, P., Clarke, M., Hempel, S., Miles, J., \& Irons, C. (2004). Criticizing and reassuring oneself: An explora- 
tion of forms, styles and reasons in female students. British Journal of Clinical Psychology, 43(1), 31-50. https://doi.org/10.1348/014466504772812959

Gilbert, P. (2010b). Training our minds in, with and for compassion. An introduction to concepts and compassion-focused exercises. Retrieved on 21.1.2019 from: http://wtm.thebreathproject. org/wp-content/uploads/2016/03/COMPAS SION-HANDOUT.pdf

Gilbert, P., \& Procter, S. (2006). Compassionate mind training for people with high shame and self-criticism: Overview and pilot study of a group therapy approach. Clinical Psychology \& Psychotherapy, 13(6), 353-379. https://doi. org/10.1002/cpp.507

Gilbert, P., \& Irons, C., (2004). A pilot exploration of the use of compassionate images in a group of self-critical people. Memory, 12(4), 507-516. https://doi.org/10.1080/09658210444000115

Gilbert, P. (1989). Human nature and suffering. Psychology Press.

Halamová, J., \& Kanovský, M. (2017). Sebasúcit a sebakritickost' - Psychometrická analýza meracích nástrojov. Bratislava: Vydavatel'stvo Univerzity Komenského.

Halamová, J., Kanovský, M., Gilbert, P., Troop, N., Zuroff, D., Hermanto, N., Petrocchi, N., Sommers-Spijkerman, M., Kirby, J., Shahar, B., Krieger, T., Matos, M., Asano, K., Yu, F., Basran, J., \& Kupeli, N. (2018). The factor structure of the Forms of Self-Criticising/Attacking \& Self-Reassuring Scale in thirteen populations. Journal of Psychopathology and Behavioral Assessment, 40(4), 736-751. https://doi. org/10.1007/s10862-018-9686-2

Halamová, J., Kanovský, M., \& Pacúchová, M. (2017). Robust psychometric analysis and factor structure of the Forms of Self-Criticizing/Attacking and Self-Reassuring Scale. Československá Psychologie, 61(4), 331-349.

Halamová, J., Koróniová, J., Kanovský, M., Kenésy Túnyiová, M., \& Kupeli, N. (2019). Psychological and physiological effects of emotion focused training for self-compassion and self-protection. Research in Psychotherapy: Psychopathology, Process and Outcome, 22, 264-279. https://doi. org/10.4081/ripppo.2019.358

Hazlett, R. L., \& Benedek, J. (2007). Measuring emotional valence to understand the user's experience of software. International Journal of Human-Computer Studies, 65(4), 306-314 https://doi.org/10.1016/i.ijhcs.2006.11.005

Kirby, J. N. (2016). Compassion interventions: The programmes, the evidence, and implications for research and practice. Psychology and Psychotherapy: Theory, Research and Practice, 90(3), 432-455. https://doi.org/10.1111/papt.12104

Kirby, J. N., Doty, J. R., Petrocchi, N., \& Gilbert, P. (2017). The current and future role of heart rate variability for assesing and training compassion. Frontiers in Public Health, 5, 40-48. https://doi. org/10.3389/fpubh.2017.00040

Koller, M. (2016). robustlmm: An R Package for Robust Estimation of Linear Mixed-Effects Models. Journal of Statistical Software, 75(6), 1-24. http://dx.doi.org/10.18637/iss.v075.i06

Künecke, J., Hildebrandt, A., Recio, G., Sommer, W., \& Wilhelm, O. (2014). Facial EMG responses to emotional expressions are related to emotion perception ability. PLOS ONE, 9(1). https://doi. org/10.1371/journal.pone.0084053

Mills, K. R. (2005). The basics of electromyography. Journal of Neurology, Neurosurgery \& Psychiatry, 76(suppl_2), ii32-ii35. http://dx.doi. org/10.1136/innp.2005.069211

Muris, P., Meesters, C., Prierik, A., \& Kock, B. D. (2015). Good for the Self: Self-compassion and other self-related construct in relation to symptoms of anxiety and depression in non-clinical youths. Journal of Child and Family Studies, 25(2), 607-617. https://doi.org/10.1007/ s10826-015-0235-2

Nakagawa, S., \& Schielzeth, H. (2013). A general and simple method for obtaining R2 from Generalized Linear Mixed-effects Models. Methods in Ecology and Evolution, 4, 133-142. https://doi. org/10.1111/j.2041-210x.2012.00261.x

Neff, K. D. (2003). Development and validation of a scale to measure self-compassion. Self and Identity, 2, 223250. https://doi.org/10.1080/15298860309027

Niedenthal, P. M., Mermillod, M., Maringer, M., \& Hess, U. (2010). The Simulation of Smiles (SIMS) model: Embodied simulation and the meaning of facial expression. Behavioral and Brain Sciences, 33(6), 417-433. https://doi.org/10.1017/ S0140525X10000865

O'Connor, R. C., \& Noyce, R. (2008). Personality and cognitive processes: Self-criticism and different types of rumination as predictors of sui- 
cidal ideation. Behaviour Research and Therapy, 46(3), 392-401. https://doi.org/10.1016/i. brat.2008.01.007

Pascual-Leone, A., \& Greenberg, L. S. (2007). Emotional processing in experiential therapy: Why "the only way is through." Journal of Consulting and Clinical Psychology, 75(6), 885-887. https:// doi.org/10.1037/0022-006X.75.6.875

Petrocchi, N., Ottaviani, C., \& Couyoumdjian, A. (2017). Compassion at the mirror: Exposure to a mirror increases the efficacy of a self-compassion manipulation in enhancing soothing positive affect and heart rate variability. The Journal of Positive Psychology, 12(6), 525-536. https:// doi.org/10.1080/17439760.2016.1209544

Pinheiro, J., Bates, D., DebRoy, S., \& Sarkar, D. (2015). nlme: Linear and Nonlinear Mixed Effects Models. https://cran.r-project.org/web/packages/nlme/index.html

Rohde, K., Adolph, D., Dietrich, D. E., \& Michalak, J. (2014). Mindful attention regulation and non-judgmental orientation in depression: A multi-method approach. Biological Psychology, 101, 36-43. https://doi.org/10.1016/i.biopsycho.2014.06.009

Sato, W., Fujimura, T., \& Suzuki, N. (2008). Enhanced facial EMG activity in response to dynamic facial expressions. International Journal of Psychophysiology, 70(1), 70-74. https://doi. org/10.1016/i.ijpsycho.2008.06.001

Schwartz, G. E., Fair, P. L., Salt, P., Mandel, M. R., \& Klerman, G. L. (1976). Facial muscle patterning to affective imagery in depressed and nondepressed subjects. Science, 192(4238), 489-491. https://doi.org/10.1126/science.1257786

Seppälä, E. M., Simon-Thomas, E., Brown, S. L. Worline, M. C., Cameron, C. D., \& Doty, J. R. (2017). The Oxford Handbook of Compassion Science. Oxford: Oxford University Press.

Sloan, D. M., Bradley, M. M., Dimoulas, E., \& Lang, P. J. (2002). Looking at facial expressions: Dysphoria and facial EMG. Biological Psychology,
60(2-3), 79-90. https://doi.org/10.1016/S03010511(02)00044-3

Strauss, C., Taylor, B. L., Gu, J., Kuyken, W., Baer, R., Jones, F., \& Cavanagh, K. (2016). What is compassion and how can we measure it? A review of definitions and measures. Clinical Psychology Review, 47, 15-27. https://doi.org/10.1016/i.cpr.2016.05.004 Suess, F., \& Rahman, R. A. (2015). Mental imagery of emotions: Electrophysiological evidence. Neurolmage, 114, 147-157. https://doi. org/10.1016/i.neuroimage.2015.03.063

Svendsen, J. L., Osnes, B., Binder, P., Dundas, I., Visted, E., Nordby, H., Schanche, E., \& Sørensen, L. (2016). Trait self-compassion reflects emotional flexibility through an association with high vagally mediated heart rate variability. Mindfulness, 7(5), 1103-1113. https://doi.org/10.1007/ s12671-016-0549-1

Werner, A. M., Tibubos, A. N., Rohrmann, S., \& Reiss, N. (2019). The clinical trait self-criticism and its relation to psychopathology: A systematic review - Update. Journal of Affective Disorders, 246, 530-547. https:// doi.org/10.1016/i.jad.2018.12.069

Whelton, W. J., \& Greenberg, L. S. (2005). Emotion in self-criticism. Personality and Individual Differences, 38(7), 1583-1595. https://doi. org/10.1016/i.paid.2004.09.024

Witvliet, C. V., Knoll, R. W., Hinman, N. G., \& Deyoung, P. A. (2010). Compassion-focused reappraisal, benefit-focused reappraisal, and rumination after an interpersonal offense: Emotion-regulation implications for subjective emotion, linguistic responses, and physiology. The Journal of Positive Psychology, 5(3), 226-242. https://doi.org/10.1080/17439761003790997

Zuroff, D. C., Sadikaj, G., Kelly, A. C., \& Leybman, M. J. (2015). Conceptualizing and measuring self-criticism as both a personality trait and a personality state. Journal of Personality Assessment, 98(1), 14-21. https://doi.org/10.1080/00 223891.2015.1044604 